\title{
ANÁLISE DA GESTÃO DE CONTAS PARA EMPRESAS DE PUBLICIDADE DE PEQUENO PORTE
}

\section{RESUMO}

Empresas que prestam serviços de publicidade têm como sua matéria prima o intelecto e o tempo de seus funcionários. Por isso, é necessário compreender quais são os atributos que classificam uma conta de cliente como uma conta de grande potencial e assim maximizar o desempenho da empresa. Este estudo tem como objetivo indicar tais atributos que denotam uma conta com grande potencial e prescrever métodos de controle para que a empresa obtenha alto desempenho com suas parcerias. Para isso, é realizado um estudo de caso, com entrevistas de profundidade e analisados os resultados à luz da visão baseada em recursos e teoria da agência.

Palavras-chave: Gestão de Contas, Visão Baseada em Recursos, Teoria da Agência, Agências de Publicidade.

\section{ACCOUNT MANAGEMENT ANALYSIS FOR SMALL ADVERTISING FIRMS}

\begin{abstract}
Firms that provide advertising services have the intellect and time of their employees as the "raw materials" of their services. Therefore, it is necessary to understand what are the attributes that classify a client account as a high potential account and thus maximize the performance of the firm. This study intends to indicate such attributes that denote an account with great potential and prescribe methods of control for the company to obtain high performance with their partners. For this, I conducted a case study, in depth interviews and analyzed the results in light of the resource-based view and agency theory.
\end{abstract}

Keywords: Account Management, Resource-based View, Agency Theory, Advertising Agencies.

Christian Falaster ${ }^{1}$

\footnotetext{
${ }^{1}$ Universidade Nove de Julho - UNINOVE, Brasil

E-mail: christianfalaster@gmail.com
} 


\section{INTRODUÇÃOO}

Empresas de publicidade atuam em um mercado estritamente de serviços, onde o desempenho intelectual e o tempo dos funcionários são matérias primas. É imprescindível para as empresas de publicidade que seus clientes se encaixem em um perfil que potencialize os ganhos - financeiros ou não - da empresa, observando os limites de tempo dos funcionários. A gestão de contas se apresenta como um mecanismo para que sejam aplicadas estratégias que objetivam o desenvolvimento de parcerias de longo prazo com clientes-chave, com maior potencial (Al-Husan \& Brennan, 2009) e excluídas as contas que não se apresentam como recursos que possam dar uma vantagem competitiva sustentável à empresa.

Este relato técnico tem como objetivo propor um melhor funcionamento para a gestão de contas de clientes em empresas de propaganda. O estudo é realizado com base no estudo do caso de uma empresa de publicidade de pequeno porte em Santa Catarina. Propomos uma análise na visão baseada em recursos para determinar os fatores que classificam uma conta de cliente como uma conta com alto potencial que pode representar vantagem competitiva sustentável para a empresa de publicidade em questão e a utilização da teoria da agência para definir métodos de controle para que estes recursos sejam prospectados.

Metodologicamente, utilizamos um estudo de caso, por meio de análise qualitativa. Para compreender a problemática da empresa em questão, foram utilizadas entrevistas em profundidade como método de coleta de dados. Após, os dados coletados são refletidos com base na teoria estudada, para construir um modelo de conta ideal.

Este relato está dividido em seis partes além desta introdução. Primeiro, é conduzida uma breve fundamentação teórica nos temas teoria da agência, visão baseada em recursos e gestão de contas. Então, são apresentadas a metodologia utilizada e a situação problema compreendida. Posteriormente, são prescritos mecanismos de incentivo e controle para os agentes e é definido um modelo de conta ideal a ser buscado pela empresa.

\section{FUNDAMENTAÇÃO TEÓRICA}

Para levantar a discussão que o presente artigo propõe, é necessário compreender a teoria da agência, a visão baseada em recursos, e o funcionamento da gestão de contas. Estes assuntos são abordados nos seguintes tópicos.

\section{Teoria da agência}

A teoria da agência vem sendo utilizada por acadêmicos de várias áreas das ciências sociais aplicadas e comportamentais. Ela é atualmente aplicada de maneira ampla para estudos empíricos e na validação de hipóteses implícitas (Martinez, 1998). O relacionamento de agência é definido por Jensen e Meckling (1976) como um contrato no qual uma ou mais pessoas - principais - se envolvem com outras - agentes - para que estas executem serviços em seu lugar. Esta relação envolve a delegação de um certo grau de tomada de decisão ao agente. A firma, nesta teoria, é visualizada como um grande feixe de contratos que se intercalam e cruzam em vários sentidos entre as partes da organização. (Martinez, 1998). O grande problema abordado pela teoria da agência é a possibilidade dos agentes assumirem comportamentos oportunistas em suas ações, ou omissões, ao visar apenas satisfação pessoal (Martinez, 1998). Desta maneira, os modelos de relações empregatícias precisam estar calcados na observabilidade das ações e na incerteza das características dos empregados e da organização (Levinthal, 1988). Caso ambas as partes envolvidas no relacionamento buscarem 
maximizar seus interesses, há grandes motivos para se acreditar que os agentes não agirão de acordo com os interesses do principal.

As relações entre o principal e o agente criam desafios para que o principal monitore as atividades do agente (Martinez, 1998). O principal pode limitar as divergências de seu interesse através da criação de incentivos apropriados para o agente e incorrendo em custos de monitoramento. Em outros casos, o principal pode pagar ao agente (custos de ligação) para que estes não tomem atitudes que contra a vontade do principal (Jensen \& Meckling, 1976). Estes são denominados mecanismos de governança, e tem o objetivo de monitorar e controlar os agentes. Entre eles, se destacam conselhos diretores, auditorias, supervisores, arranjos estruturais, entre outros (Levinthal, 1988). A utilização destes mecanismos acarreta no estabelecimento de custos de monitoramento, são eles os custos do principal, custos de ligação com os agentes e a perda residual (Jensen \& Meckling, 1976). Dentre os mecanismos de compensação oferecidos ao agente, é importante ressaltar que estes não devem ser pagamentos fixos, mas sim pagamentos pautados como uma expressão das recompensas em relação ao lucro da firma obtido devido ao agente. Porém, estes mecanismos precisam ser pensados de maneira a não acarretar em dissidências posteriores.

\section{Visão baseada em recursos.}

A visão baseada em recursos é uma análise de como as firmas competem, voltada para os recursos internos da organização, que cresceu em popularidade ao final dos anos 80 (Peteraf, 1993). Recursos são forças que as empresas podem obter para implementar suas estratégias (Barney, 1991). É possível também entender recursos como, por exemplo, nomes de marca, conhecimento interno, posicionamento de profissionais competentes, contratos, maquinário, procedimentos, capital, entre outros. Estes recursos podem ser tanto tangíveis quanto intangíveis (Wernerfelt, 1986). A empresa obtém vantagem competitiva sustentável (sustained competitive advantage) quando essa empresa emprega uma estratégia que não está sendo empregada simultaneamente pela sua concorrência e quando estas outras empresas não conseguem duplicar os benefícios desta estratégia (Barney, 1991). De acordo com a teoria de Barney (1991), para que um recurso caracterize uma vantagem competitiva sustentável, é necessário que apresente valor, ser raro, ser imperfeitamente imitável e insubstituível. Em seu trabalho posterior, Barney (1997) definiu a possibilidade de exploração do recurso pela organização como o atributo final da avaliação. Esta relação pode ser vista no Quadro 1:

Quadro 1 - VRIO

\begin{tabular}{|c|c|c|c|}
\hline Valor & Raridade & Imitação & Organização \\
\hline $\begin{array}{c}\text { Agrega } \\
\text { valor/traz } \\
\text { valor à } \\
\text { organização }\end{array}$ & $\begin{array}{c}\text { É de } \\
\text { difícil } \\
\text { acesso }\end{array}$ & $\begin{array}{c}\text { Não pode ser } \\
\text { copiada pelos } \\
\text { concorrentes }\end{array}$ & $\begin{array}{c}\text { A } \\
\text { organização } \\
\text { é capaz de } \\
\text { explora-lo } \\
\text { efetivamente }\end{array}$ \\
\hline
\end{tabular}

Fonte: Elaborado pelo autor (2014), baseado em Barney (1991) e Barney (1997). 


\section{Gestão de contas}

A gestão estratégica de contas é um tópico de crescente interesse para acadêmicos e profissionais, principalmente nas áreas de marketing e vendas (Al-Husan \& Brennan, 2009). Em resumo, a gestão estratégica de contas busca analisar a co-criação de valor por meio de parcerias entre empresa e clientes estrategicamente importantes (Storbacka, 2012).

É possível posicionar o relacionamento de compra e venda entre empresa e cliente entre cinco níveis, são eles transações pontuais, transações repetidas, relacionamento de longo prazo, alianças e integração vertical (Lambe \& Spekman, 1997). Dentro destes níveis, os maiores benefícios podem ser encontrados, para ambas as partes, nos relacionamentos superiores aos "de longo prazo" (Al-Husan \& Brennan, 2009). Para que o relacionamento entre as partes evolua, é indicado um programa, ou seja, um planejamento de relação com o cliente. Este programa necessita visar que sejam asseguradas a confiança e harmonia para gerar lealdade do cliente. Maximizada a receita proveniente do cliente. Desenvolvida uma imagem positiva da empresa com o parceiro e por fim, seja construída uma parceria estratégica entre empresa e cliente (Al-Husan \& Brennan, 2009).

\section{METODOLOGIA}

O procedimento metodológico para este trabalho é um estudo de caso qualitativo, por se tratar de um estudo aprofundado de um fenômeno em um contexto social, busca uma construção teórica da realidade e envolve a observação direta do observador (YIN, 2001). Para Yin (2001), os estudos de caso, permitem o pesquisador estudar a fundo fenômenos contemporâneos (Yin, 2001) analisando internamente a organização estudada. O método de coleta de dados escolhido foi a entrevista em profundidade com o proprietário, o diretor de atendimento e os executivos de contas da empresa. A triangulação dos dados ocorreu pela análise das respostas de entrevistados em diferentes níveis hierárquicos da organização. A estrutura de relato técnico utilizada para escrever este estudo é defendida por Biancolino, Kniess, Maccari, \& Rabechini Jr. (2012).

No total, foram entrevistados seis integrantes da empresa, o diretor-proprietário, o diretor de atendimento e os quatro executivos de contas presentes na empresa. $\mathrm{O}$ roteiro de pesquisa, proposto para o presente estudo segue a forma de:

1) Entrevista em profundidade com o diretor-proprietário da empresa, diretor de atendimento e com os executivos de contas, onde foram realizadas as perguntas abertas:

a) "Como funciona o processo de prospecção de clientes na empresa? Quais são os fatores analisados para decidir prospectar ou não a conta?";

b) "Como funciona a gestão das contas na agência, na decisão de manter ou não uma parceria".

c) "Quais são os métodos de incentivo para os executivos de contas para a prospecção dos clientes?". (Pergunta realizada apenas ao diretor-proprietário).

d) "Você acredita que os executivos de conta agem de maneira a garantir um desempenho em longo prazo para a empresa? Eles prospectam com base no futuro da conta na empresa ou apenas na comissão?". (Pergunta realizada apenas ao diretorproprietário).

e) "Como é o cliente perfeito?".

2) As entrevistas realizadas foram transcritas manualmente para a melhor compreensão das respostas. 
3) As transcrições foram analisadas de maneira a trazer insights, reunir os métodos utilizados na empresa e apontar os verdadeiros problemas.

\section{SITUAÇÃO-PROBLEMA}

\section{Contextualização do caso}

A agência de publicidade investigada tem pequeno porte, por isso, sua estrutura não permite trabalhos para clientes que estejam fora de um perfil de alto desempenho. É necessário estabelecer critérios que definam o cliente como de alto desempenho ou não, tanto de maneira financeira quanto por outros motivos mais subjetivos. Nosso objetivo é desenvolver indicadores que determinam se o cliente trará uma vantagem competitiva para a agência. Este caso foi escolhido por se tratar de uma empresa que tem um histórico de momentos positivos, onde houve a necessidade de gerenciar as contas de clientes para priorizar os mais potentes.

A organização se define da seguinte maneira:

- Natureza: Privada e Ltda;

- Propriedade do capital: Nacional;

- Setor de atividade: Serviços.

- Descrição sumária: Agência de publicidade.

- Porte e localização: Pequeno porte - Blumenau, SC.

- Número de colaboradores: 40.

- Faturamento: Aproximadamente R \$3.000.000,00/ano

- Breve histórico da organização: Empresa líder no segmento na região, entre as maiores agências de publicidade do estado de Santa Catarina. Têm 24 anos de existência e, entre seus clientes, atende clientes privados e estatais.

- Mercado em que atua: Atende clientes, sem um foco específico, por toda a região Sul do país.

- Principais concorrentes: Free Comunicação, Seven Comunicação, Propague Comunicação, BZZ Comunicação, D’Araújo Comunicação.

- Estrutura organizacional: Um diretor geral, um diretor de mídia, um diretor de atendimento, um diretor de criação, um diretor financeiro, cada qual com sua equipe setorial.

\section{Resultados obtidos}

As respostas obtidas por meio das entrevistas em profundidade definiram pontos principais do modus operandi da empresa estudada, de acordo com o quadro 2 : 
Quadro 2. Respostas obtidas:

\begin{tabular}{|c|c|}
\hline Item: & Principais respostas obtidas: \\
\hline $\begin{array}{l}\text { Principais atributos } \\
\text { em um cliente. }\end{array}$ & $\begin{array}{l}\text { De acordo com todos os entrevistados, existe sempre uma análise da } \\
\text { conta a ser prospectada, nesta análise, os entrevistados destacaram } \\
\text { que são avaliadas: Compatibilidade de tamanho de empresa; } \\
\text { visibilidade; histórico de verba publicitária; potencial para } \\
\text { investimento; abrangência geográfica; competência na área de } \\
\text { marketing e publicidade; qualidade do produto; crescimento } \\
\text { econômico do mercado da conta. Também foi ressaltada uma } \\
\text { necessidade de estabelecer uma variedade de mercado de atuação } \\
\text { dos clientes, para evitar problemas com baixas econômicas em } \\
\text { mercados específicos. Uma das questões principais apontadas pelos } \\
\text { respondentes foi o relacionamento, de acordo com eles, é essencial } \\
\text { que seja possível estabelecer um bom relacionamento com o } \\
\text { representante da conta, de maneira a desenvolver uma parceria de } \\
\text { longo prazo. }\end{array}$ \\
\hline $\begin{array}{l}\text { Avaliação do } \\
\text { desempenho da } \\
\text { conta. }\end{array}$ & $\begin{array}{l}\text { A empresa busca a coerência entre o número de trabalhos por conta } \\
\text { e o faturamento desta conta. Atualmente estabelece um número de } \\
\text { trabalhos máximo por mês nos contratos, mas não um número de } \\
\text { horas trabalhadas por trabalho. O entrevistado C indica que "muitas } \\
\text { vezes acontecia de haver muitos trabalhos para um cliente com } \\
\text { pouco faturamento, assim, acabamos pagando para trabalhar, mas } \\
\text { estamos mudando isso". O entrevistado A concorda, e afirma que } \\
\text { não existe a intenção de encerrar qualquer relação com contas da } \\
\text { agência, mas sim torna-la uma conta de alto desempenho por meio } \\
\text { de negociação com o cliente. O relacionamento foi apontado pela } \\
\text { maioria dos entrevistados como fator determinante na manutenção } \\
\text { da conta e no desenvolvimento de uma conta de alto desempenho. }\end{array}$ \\
\hline $\begin{array}{l}\text { Métodos de } \\
\text { incentivo. }\end{array}$ & $\begin{array}{l}\text { Atualmente trabalha com comissão por faturamento dos clientes } \\
\text { prospectados, os contratos fechados pelo próprio executivo rendem } \\
\text { maiores comissões. Porém, não há incentivos para que os } \\
\text { executivos busquem clientes que demandem um alto desempenho } \\
\text { em relação faturamento versus horas trabalhadas. }\end{array}$ \\
\hline $\begin{array}{l}\text { Coerência entre } \\
\text { intenções. }\end{array}$ & $\begin{array}{l}\text { A partir das respostas de todos os entrevistados, foi observado um } \\
\text { forte alinhamento de intenções entre os executivos e o diretor- } \\
\text { proprietário da empresa, não observados problemas ou hábitos } \\
\text { nocivos por meio dos executivos. }\end{array}$ \\
\hline
\end{tabular}

Fonte: Elaborado pelo autor com os dados coletados (2014).

\section{MECANISMOS PROPOSTOS}

Conforme o intuito prescritivo que o relato técnico sugere, definem-se aqui os mecanismos propostos para aperfeiçoar a gestão de contas e incentivar os executivos de contas da empresa. O primeiro mecanismo diz respeito a cinco fatores que juntos se encaixam nas características "VRIO" dos recursos de Barney (1991, 1997). Neste caso, é adotado o conceito de conta publicitária do cliente como um recurso possuído pela agência. $\mathrm{O}$ segundo mecanismo prescritivo baseia-se nos estudos sobre teoria da agência (Jensen \& Meckling, 
1976; Levinthal, 1988; Martinez, 1998; Shapiro, 2005) e propõe um método de controle para incentivar os executivos de contas a desenvolver parcerias que demandem poucas horas de trabalho e ofereçam alto faturamento.

\section{Atributos para o alto desempenho}

Para definir uma conta publicitária como um recurso que trará vantagem competitiva sustentável, é necessário que ela possua o maior número possível dos seguintes atributos. Observando que esta prescrição leva em consideração que quanto mais atributos entre estes ela possuir, maior será a vantagem competitiva para a empresa detentora da conta publicitária, definindo assim a conta como de alto desempenho:

- Retorno financeiro: O retorno financeiro é de evidente importância para definir uma conta como de alto desempenho. O pensamento comum é de que quanto maior for o retorno financeiro da conta, maior é o potencial dela, porém, é necessário ponderar os outros atributos.

- Ramo de trabalho raro: Quando a conta representa um cliente de um ramo incomum, onde não existem muitos concorrentes, ela automaticamente se torna uma vantagem competitiva sustentável para a agência de publicidade, em relação aos seus próprios concorrentes. Conforme apontado pelos entrevistados, é necessário buscar clientes de ramos diferentes para que seja garantida uma estabilidade frente a mudanças econômicas. Isto é ainda mais evidente devido ao fato das agências respeitarem, de maneira geral, um modo de operação onde não possuem dois clientes do mesmo ramo na mesma região, para respeitar o sigilo e competitividade entre concorrentes.

- Cliente com perfil inimitável: É possível obter vantagem competitiva em relação às empresas de publicidade concorrentes se a conta for única em si, inimitável pelo próprio perfil do cliente ou seu posicionamento de comunicação. Sendo por contexto histórico, ambiguidade causal, ou complexidade social. Como por exemplo, o Banco do Brasil, pelo seu contexto histórico de primeiro banco no país, ou a Nike como referência como marca de esporte. Outro ponto que torna uma conta um recurso inimitável é seu nível de relacionamento com a empresa de publicidade, sendo ele de longo-prazo, uma aliança ou uma integração vertical, obtidas por tempo e qualidade da gestão do relacionamento.

- Alta relação valor/horas trabalhadas: Um fator de grande importância para uma conta ser considerada de alto desempenho é a relação valor/horas de trabalho. Quanto mais alta for a relação, trabalhando pouco e faturando um valor elevado, maior será o desempenho da conta.

Estes atributos se encaixam na teoria de Barney (1991) de acordo com o quadro 3: 
Quadro 3 - Atributos da conta

\begin{tabular}{|l|l|}
\hline $\begin{array}{l}\text { Atributos } \\
\text { VRIO: }\end{array}$ & Atributos da conta: \\
\hline Valioso & Retorno financeiro; \\
\hline Raro & Variedade/raridade do ramo de atuação \\
\hline Inimitável & Perfil/Relacionamento Inimitável \\
\hline $\begin{array}{l}\text { Explorado } \\
\text { pela } \\
\text { Organização }\end{array}$ & Alta relação valor/horas trabalhadas \\
\hline
\end{tabular}

Fonte: Elaborado pelo autor (2014).

\section{Mecanismo de incentivo aos executivos}

Em seguida, propomos um mecanismo de controle para que os executivos priorizem os clientes que apresentarem os atributos apresentados anteriormente. Conforme as teorias de Jensen \& Meckling (1976), Levinthal (1988), Martinez (1998) e Shapiro (2005), é necessário priorizar o incentivo aos agentes, porém, este incentivo não pode fazer desvirtuar a intenção do agente em relação ao principal.

Como não é possível quantificar (de maneira generalizada) a raridade e a inimitabilidade das contas, este artigo se atém a estabelecer um sistema de incentivo levando em consideração o retorno financeiro e a relação entre valor e horas de trabalho. Este sistema de incentivos proposto tem duas variáveis, são elas Valor, sendo este o valor faturado pela empresa por meio da conta, e o número de horas trabalhadas pela equipe, enquanto realiza as tarefas exigidas para a conta. Este fator é melhor calculado quando baseado nas médias mensais. No sistema de incentivo proposto, o principal deverá incentivar de maneira financeira os agentes, utilizando como cálculo o valor total faturado dividido pelas horas trabalhadas. Assim busca-se determinar as atitudes dos executivos em poupar o tempo e trabalho dos demais colaboradores da empresa e maximizar assim os lucros.

Para isto, calculamos o incentivo. É tomado o nome " $x$ " para determinar o custo médio por hora trabalhada na empresa. Este cálculo compreende custos fixos, folha de pagamento, custos variáveis médios entre todos os outros custos da empresa, divididos pelo número de horas trabalhadas somadas por todos os colaboradores. Designa-se o faturamento mensal proveniente da conta como "y", e o número de horas trabalhadas como "h". O quociente entre o faturamento mensal e o número de horas trabalhado é denominado por " $\mathrm{z}$ ".

Determinamos o seguinte cálculo para definir o nível do incentivo ao agente:

$$
\frac{\mathrm{y}}{\mathrm{h}}=\mathrm{z}
$$

Para determinar o nível de incentivo ao agente, deve ser utilizada a seguinte referência no Quadro 3:

Quadro 3-Círculos de incentivo:

\begin{tabular}{|l|l|}
\hline Círculo 1 & $\mathrm{z}>\mathrm{x}$ \\
\hline Círculo 2 & $\mathrm{z}>2 \mathrm{x}$ \\
\hline Círculo 3 & $\mathrm{z}>3 \mathrm{x}$ \\
\hline
\end{tabular}

Fonte: Elaborado pelo autor (2014) 
O valor referente ao incentivo cabe ser ajustado de acordo com a situação momentânea da organização. Estes cálculos devem ser feitos individualmente levando em consideração cada conta de cada executivo, para assim evitar o julgamento dos outros executivos pela conduta de apenas um.

\section{RESULTADOS ESPERADOS}

Os resultados esperados referentes ao uso dos dois mecanismos são simples. É esperado que os agentes, executivos de contas passem a prospectar contas que se encaixem nos atributos indicados como essenciais para a vantagem competitiva. Por outro lado, é esperado que, por meio do mecanismo de incentivo aos executivos de contas, estes privilegiem as contas com maior quociente entre valor faturado e hora trabalhada. É necessário, porém, uma supervisão constante da conduta dos executivos, para que este método de incentivo não subjugue os demais atributos positivos que levam à vantagem competitiva sustentável.

Com a aplicação de ambas as prescrições, a empresa atingirá vantagem competitiva sustentável em relação a seus concorrentes, maximizará o lucro e investirá nas contas de alto desempenho. Desta maneira, o proprietário cumprirá sua principal meta, aumentar o valor da organização (Jensen \& Meckling, 1976), além de obter lucros maiores devido à otimização do trabalho com base no investimento em relacionamentos de longo-prazo com clientes dentro do perfil de alto potencial (Al-Husan \& Brennan, 2009; Storbacka, 2012).

\section{CONSIDERAÇÕES FINAIS}

A conduta aplicada atualmente pela empresa de publicidade estudada já prima por atributos que corroboram as teorias de Barney (1991) e Al-Husan e Brennan (2009), porém, de uma maneira pouco estruturada e ainda muito intuitiva. É necessária a experimentação dos processos aqui prescritos para que seja provada sua eficiência prática.

É importante que sejam observadas as limitações deste estudo. Foi apenas abordada uma empresa de publicidade como referência, o que pode acarretar em diferenças com relação a casos de diferentes portes e localizações geográficas. Recomendamos a replicação do estudo em diferentes empresas do mesmo ramo para maior apuração. Outra limitação é a extensão das análises, voltadas para um relato técnico com implicações para a academia e a prática. Para uma maior averiguação, é recomendado que os futuros trabalhos sejam realizados em formato de artigo científico, proporcionando conclusões mais profundas. 


\section{REFERÊNCIAS}

Al-Husan, F. B., \& Brennan, R. (2009). Strategic account management in an emerging economy. Journal of Business \& Industrial Marketing, 24(8), 611-620.

Barney, J. (1991). Firm resources and sustained competitive advantage. Journal of Management, 17(1), 99-120.

Barney J. (1997). Gaining and Sustaining Competitive Advantage. Addison-Wesley: Reading, MA.

Biancolino, C. A., Kniess, C. T., Maccari, E. A., \& Rabechini Jr., R. (2012). Protocolo Para Elaboração De Relatos De Produção Técnica. Revista de Gestão E Projetos, 3(2), 294 307.

Jensen, M. C., \& Meckling, W. H. (1976). Theory of the Firm : Managerial Behavior, Agency Costs and Ownership Structure. Journal of Financial Economics, 3(4), 305-360.

Lambe, C.J. and Spekman, R.E. (1997), "National account management: large account selling or buyer-supplier alliance?”, Journal of Personal Selling and Sales Management, 17(4) 61-74.

Levinthal, D. (1988). A survey of agency models of organizations. Journal of Economic Behavior \& Organization, 9(1)

Martinez, A. (1998). Agency theory na pesquisa contábil. ENCONTRO DA ANPADENANPAD, 1-14.

Peteraf, M. (1993). The cornerstones of competitive advantage: A resource based view. Strategic Management Journal, 14(3), 179-191.

Shapiro, S. P. (2005). Agency Theory. Annual Review of Sociology, 31(1), 263-284.

Storbacka, K. (2012). Strategic account management programs: alignment of design elements and management practices. Journal of Business \& Industrial Marketing, 27(4), 259274.

Wernerfelt, B. (1984). A Resource-based View of the Firm. Strategic Management Journal. 5(2) 171.

Yin, R. K. (2001). Estudo de caso: planejamento e métodos. Porto Alegre: Bookman. 